\title{
Colonization of Mutualistic Mycorrhizal and Parasitic Blast Fungi Requires OsRAM2-Regulated Fatty Acid Biosynthesis in Rice
}

\author{
Huiling Dai, ${ }^{2}$ Xiaowei Zhang, ${ }^{2}$ Boyu Zhao, ${ }^{1}$ Jincai Shi, ${ }^{2}$ Chi Zhang, ${ }^{2}$ Gang Wang, ${ }^{2}$ Nan $\mathrm{Yu},{ }^{1, \dagger}$ and \\ Ertao Wang ${ }^{2, \dagger}$ \\ ${ }^{1}$ Shanghai Key Laboratory of Plant Molecular Sciences, College of Life Sciences, Shanghai Normal University, Shanghai \\ 200234, China \\ ${ }^{2}$ National Key Laboratory of Plant Molecular Genetics, CAS Center for Excellence in Molecular Plant Sciences, Institute of \\ Plant Physiology and Ecology, SIBS, Chinese Academy of Sciences, Shanghai 200032, China
}

Accepted 20 December 2021.

\begin{abstract}
Arbuscular mycorrhizal (AM) fungi form a mutual association with the majority of land plants, including most angiosperms of the dicotyledon and monocotyledon lineages. The symbiosis is based upon bidirectional nutrient exchange between the host and symbiont that occurs between inner cortical cells of the root and branched AM hyphae called arbuscules that develop within these cells. Lipid transport and its regulation during the symbiosis have been intensively investigated in dicotyledon plants, especially legumes. Here, we characterize $O S R A M 2$ and $O s R A M 2 L$, homologs of Medicago truncatula $R A M 2$, and found that plants defective in OsRAM2 were unable to be colonized by AM fungi and showed impaired colonization by Magnaporthe oryzae. The induction of OsRAM2 and OsRAM2L is dependent on OsRAM1 and the common symbiosis signaling pathway pathway genes $C C A M K$ and $C Y C L O P S$, while overexpression of $O S R A M 1$ results in increased expression of $O S R A M 2$ and OsRAM2L. Collectively, our data show that the function and regulation of $O S R A M 2$ is conserved in monocot and dicot plants and reveals that, similar to mutualistic fungi, pathogenic fungi have recruited RAM2-mediated fatty acid biosynthesis to facilitate invasion.
\end{abstract}

Keywords: AM symbiosis, arbuscular mycorrhiza, M. oryzae infection, mycorrhizal interactions, OsRAM2, rice

${ }^{\dagger}$ Corresponding authors: N. Yu; nyu@ @ shnu.edu.cn, and

E. Wang; etwang@cemps.ac.cn

H. Dai, X. Zhang, and B. Zhao contributed equally to this article.

Funding: Support was provided by the National Science Foundation (31870218, 32088102, 31730103, 31825003, and 32050081), National Key R\&D Program of China (2019YFA0904703 and 2016YFA0500502), and the Strategic Priority Research Program "Molecular Mechanism of Plant Growth and Development" of the Chinese Academy of Sciences (XDB27040207).

*The $\boldsymbol{e}$-Xtra logo stands for "electronic extra" and indicates that a supplementary table and supplementary figures are published online.

The author(s) declare no conflict of interest.

(c) (1) () $\odot$ Copyright $\odot 2022$ The Author(s). This is an open access article (c)
The arbuscular mycorrhizal (AM) symbiosis is an ancient and ubiquitous beneficial mutualism between fungi belonging to subphylum Glomeromycotina and over $80 \%$ of terrestrial plants, including important crops such as maize (Zea mays), wheat (Triticum aestivum), and rice (Oryza sativa) (Brundrett and Tedersoo 2018; Genre et al. 2020). The AM association can facilitate plant uptake of soil phosphorus and nitrogen as well as increase plant local and systemic disease resistance (Liu et al. 2007; Parniske 2008; Smith and Read. 2008) whereas, in exchange, plants spare up to $20 \%$ of photosynthate for AM fungi for their growth and proliferation (Chiu and Paszkowski 2019; Genre et al. 2020; Graham et al. 1996; Jiang et al. 2017; Keymer et al. 2017; Luginbuehl et al. 2017; Wang et al. 2017). This nutrient exchange takes place through tree-shaped, subcellular structures called arbuscules that are formed in cortical cells of the host root (Choi et al. 2018; Genre et al. 2005, 2008; Gutjahr and Parniske 2013; Wang et al. 2017).

The symbiosis is established through reciprocal signaling and recognition between the host plant and AM fungi. Plant-derived strigolactones increased the fungal release of short-chain chitooligosaccharides (CO4 and CO5) and lipo-chitooligosaccharides (Akiyama et al. 2005; Besserer et al. 2006; Genre et al. 2013; Maillet et al. 2011), called mycorrhizal factors. In rice, the lysin motif (LysM)-containing receptor kinase OsMYR1 was shown to bind $\mathrm{CO} 4$, which promotes it to interact with OsCERK1 (Zhang et al. 2015; He et al. 2019) to activate the common symbiosis signaling pathway (CSSP) shared by AM symbiosis and nodulation (Oldroyd 2013; Zipfel and Oldroyd 2017). Central to the activation of symbiosis signaling is the induction of nuclear calcium oscillations which are decoded by a calcium- and calmodulin-dependent serine/threonine protein kinase (CCaMK) and its interacting protein CYCLOPS (Gutjahr et al. 2008; Horváth et al. 2011; Lévy et al. 2004; Messinese et al. 2007; Ovchinnikova et al. 2011; Singh and Parniske 2012; Singh et al. 2014; Yano et al. 2008). The lone DELLA homolog in rice (slender rice 1), a suppressor of gibberellic acid signaling (Sun 2011), can interact with CYCLOPS and promote CCaMK-CYCLOPS complex formation to regulate symbiosis (Floss et al. 2013; Jin et al. 2016; Yu et al. 2014). As a GRAS family member, DELLA can form a complex with other two GRAS proteins, DELLA INTERACTION PROTEIN 1 and REDUCED ARBUSCULE MYCORRHIZAL 1 (RAM1) to directly or indirectly regulate expression of mycorrhizal-associated genes such as EXO70I, FatM, RAM2, STR, and PT4 and, thus, control mycorrhizal colonization (Bravo et al. 2017; Floss et al. 2013; Foo et al. 2013; 
Gobbato et al. 2012, 2013; Müller et al. 2020; Park et al. 2015; Rich et al. 2015; Xue et al. 2015; Yu et al. 2014).

$R A M 1$ is regulated by DELLA, CYCLOPS, and WRI5a as well as OsPHRs (Jiang et al. 2018; Pimprikar et al. 2016; Shi et al. 2021; Yu et al. 2014), and it is required in mycorrhizal infection, arbuscule development, and senescence in Medicago truncatula, Lotus japonicus, Petunia spp., Brachypodium distachyon, and rice (Gobbato et al. 2013; Müller et al. 2020; Park et al. 2015; Pimprikar et al. 2016; Rich et al. 2015; Shi et al. 2021; Xue et al. 2015; Yu et al. 2014). In turn, RAMI can regulate the AM symbiosis-induced genes WRI5a, RAM2, FatM, and $S T R$, which function in lipid accumulation and transfer from the plant to AM fungi (Bravo et al. 2017; Gobbato et al. 2012, 2013; Gutjahr et al. 2012; Jiang et al. 2017, 2018; Keymer et al. 2017; Luginbuehl et al. 2017; Müller et al. 2020).

RAM2, a glycerol-3-phosphate acyl transferase, is required for synthesis of 2-monoacylglycerols, which might be transported from the plant root to the AM fungus by STR and STR2 (Bravo et al. 2017; Gobbato et al. 2013; Jiang et al. 2017, 2018; Keymer et al. 2017; Luginbuehl et al. 2017; Wang et al. 2012; Zhang et al. 2010), and production of cutin monomers (Wang et al. 2012). MtSTR encodes a periarbuscular membranelocalized $\mathrm{ABC}$ transporter that is regulated by the AP2/EREBP transcription factor WRI5a and GRAS protein RAM1 (Jiang et al. 2017, 2018; Park et al. 2015; Zhang et al. 2010). RAM2 was reported as a direct target of RAM1 (Gobbato et al. 2012). In $M$. truncatula, ram2 was defective in hyphopodia formation and arbuscule formation by AM fungi as well as in oomycete pathogen infection (Bravo et al. 2017; Wang et al. 2012). However, the function of $R A M 2$ in monocots remains unknown. In this study, we identified $R A M 2$ homologs in rice named $O s R A M 2$ and $O S R A M 2 L$ and found OsRAM2 is required for mycorrhizal colonization and infection by the fungal parasite Magnaporthe oryzae.

\section{RESULTS}

\section{$O s R A M 2$ and $O s R A M 2 L$ are induced upon AM colonization.}

We identified two rice proteins that grouped in the same phylogenetic clade as Medicago truncatula RAM2 in O. sativa, which were named OsRAM2 and OsRAM2L (Fig. 1A). To study their expression patterns in rice, we collected roots, stems, and leaves from AM-inoculated and mock-inoculated plants. Unlike in stems, leaves, and mock-inoculated tissues, $O s R A M 2$ and $O s R A M 2 L$ were substantially expressed in roots colonized by AM fungi, with OsRAM2 showing higher expression (Fig. 1B and C). The same patterns were reported with RNA sequencing of mycorrhizal-colonized rice roots (Shi et al. 2021). OsRAM2 and OsRAM2L were induced in roots after AM colonization, with colonization levels increasing over time (Fig. 2A and B; Supplementary Fig. S1A), and with OsRAM2 having consistently over 30-fold higher expression than OsRAM $2 L$ in AM-colonized roots. The transcription levels of OsRAM2 and OsRAM2L were reduced to approximately $30 \%$ under high-phosphate conditions that attenuate mycorrhizal symbiosis by up to $50 \%$ (Fig. $2 \mathrm{C}$ and D; Supplementary Fig. $\mathrm{S} 2)$. Taken together, these results indicate that OsRAM2 expression is highly correlated with mycorrhiza.

To precisely visualize OSRAM2 expression in the AM symbiosis, we generated a reporter construct containing a 3-kb OsRAM2 promoter driving $\beta$-glucuronidase (GUS) and evaluated GUS expression in mycorrhizal roots. We found that GUS was specifically expressed in cortical cells containing arbuscules (Fig. 2E), consistent with what was observed for $R A M 2$ in $M$. truncatula (Gobbato et al. 2013), further suggesting that OsRAM2 might be involved in the AM symbiosis.

\section{Mycorrhizal colonization was impaired in Osram2 and Osram2/Osram $2 l$.}

To further investigate the function of OsRAM2 and OsRAM2L in the mycorrhizal symbiosis, we designed clustered regularly interspaced short palindromic repeat (CRISPR)/Cas9 constructs to individually target $O S R A M 2$ and $O S R A M 2 L$ and used these constructs to generate transgenic plants. The OsRAM2 and $O s R A M 2 L$ of the transgenic lines were successfully edited by their respective guides. An Osram2 allele with a single-nucleotide insertion, resulting in premature stop codon and producing a predicted truncated protein of 50 amino acids, was isolated (Fig. 3A). A singlenucleotide insertion in $O s R A M 2 L$ led to a frame shift from the 60th amino acid and stop at $3^{\prime}$ untranslated region, producing a mutated protein of 544 amino acids (Fig. 3B). The functional domains of OsRAM2 and OsRAM2L are localized in the C termini, suggesting that the truncated or mutated proteins are nonfunctional. We then obtained an Osram $2 / O \operatorname{sram} 2 l$ double mutant through hybridization.

Mycorrhizal infected roots of Osram2 and Osram2/Osram 21 were collected at 6 weeks postinoculation (wpi). Compared with a $50 \%$ colonization level in the wild type (WT), Osram 2 roots displayed dramatically reduced colonization, which was limited to the occasional formation of intercellular hyphae and stunted arbuscules (Fig. 3C and D). In rare cases, the hyphae were able to penetrate into cortical cells but could not branch normally (Fig. 3C). Consistent with the phenotype observed for Osram2, hyphae and arbuscules were rarely seen in Osram $2 / O s r a m 2 l$ roots (Fig. 3C and D). No obvious differences in phenotype between Osram2/Osram $2 l$ and Osram 2 were observed, suggesting that $O S R A M 2 L$ makes a limited contribution to mycorrhizal symbiosis. We then assayed the expression of $O s R A M 2$ and $O s R A M 2 L$ in Osram 2 and Osram2/Osram $2 l$ mutants in mycorrhizal colonized and mock-inoculated roots. OsRAM2 expression was almost abolished in both mutants, while OsRAM2L expression was reduced to approximately $30 \%$ in Osram 2 and $50 \%$ in Osram $2 /$ Osram $2 l$ mutants after mycorrhizal colonization (Fig. $3 \mathrm{E}$ and $\mathrm{F})$.

In addition, to further validate the requirement of $O S R A M 2$ and $O S R A M 2 L$ in the symbiosis, we surveyed the expression of several AM marker genes in Osram 2 and Osram $2 / O s r a m 2 l$. The transcript levels of five marker genes, including two early-stage mycorrhizal-specific marker genes, OsAM1 and OsAM3 (Gutjahr et al. 2008; Yu et al. 2014; Zhang et al. 2015), and three late-stage marker genes, OsAM14, OsHA1, and OsPT11 (Gutjahr et al. 2008; Wang et al. 2014; Yu et al. 2014; Zhang et al. 2015), were reduced in Osram2- and Osram2/Osram2l-colonized roots (Fig. 4 ), consistent with the reduction in mycorrhizal colonization. Taken together, we concluded that $O s R A M 2$ is involved in mycorrhizal fungal infection and colonization in the cortex cell as well as arbuscule development.

\section{Induction of $O S R A M 2$ and $O S R A M 2 L$ are dependent on OsRAM1, CCaMK, and CYCLOPS.}

RAM1, a GRAS-domain transcription factor, was proven to be involved in AM symbiosis in dicots and monocots (Gobbato et al. 2012, 2013; Müller et al. 2020; Park et al. 2015; Pimprikar et al. 2016; Rich et al. 2015; Shi et al. 2021; Xue et al. 2015; Yu et al. 2014). In $M$. truncatula, RAM1 directly regulates RAM2 expression through associating with the RAM2 promoter (Gobbato et al. 2012). In $B$. distachyon, similar to MtRAM2 in M. truncatula, BdRAMI expression increased over time with increasing mycorrhizal colonization (Müller et al. 2020). BdRAMI overexpression constitutively elevated $B d R A M 2$ expression in both the shoot and roots (Müller et al. 2020). To further identify whether OSRAM2 is regulated by $O s R A M 1$, we examined the expression pattern of OsRAM2 and $O s R A M 2 L$ in the Osraml mutant and OsRAM1-overexpressing rice roots. We found that the transcript levels of OsRAM2 and OSRAM2L 

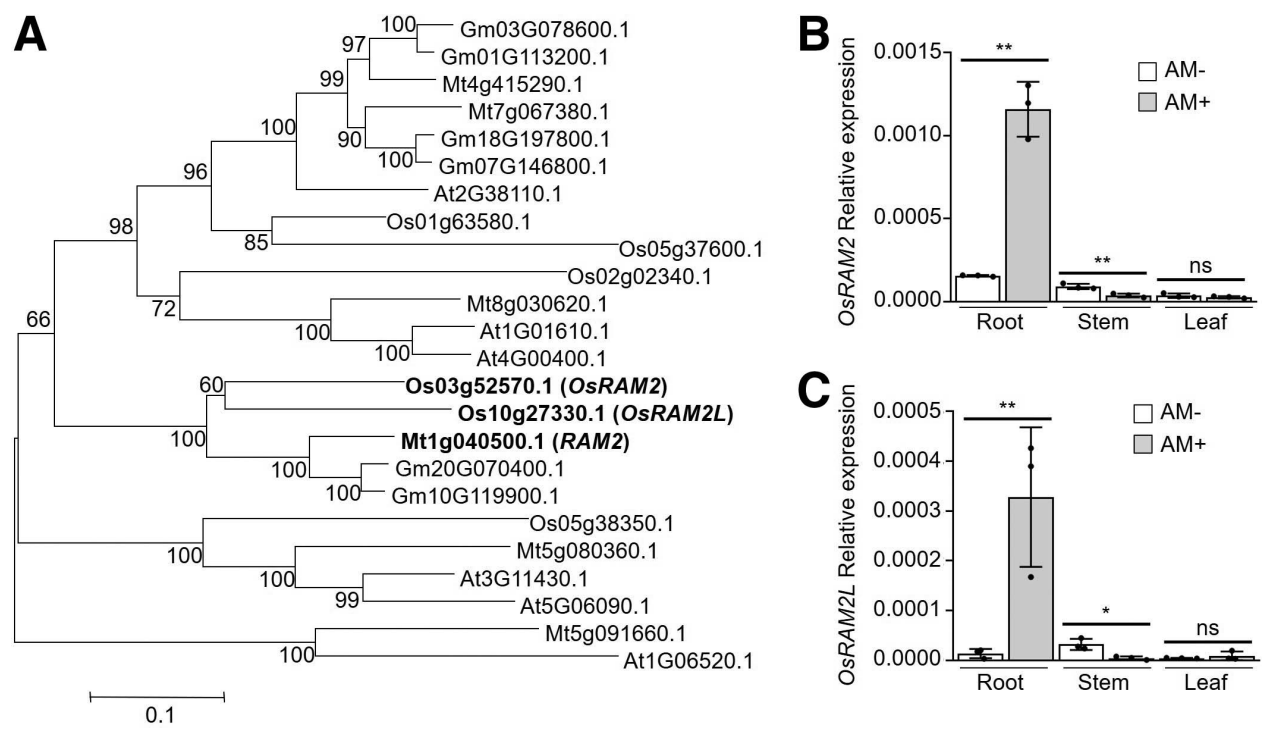

Fig. 1. Oryza sativa orthologs of RAM2 are induced in roots colonized by Rhizophagus irregularis. A, Phylogenetic tree of MtRAM2 with homologs from Medicago truncatula $(\mathrm{Mt})$, Glycine max $(\mathrm{Gm})$, Oryza sativa $(\mathrm{Os})$, and Arabidopsis thaliana $(A t)$ was constructed using a maximum-likelihood algorithm in MEGA-X with 1,000 bootstraps value. B, OsRAM2 expression in the roots, stems, and leaves of arbuscular mycorrhizal (AM)-colonized (AM+) or noncolonized (AM-) plants at 6 weeks postinoculation (wpi). A higher abundance of OsRAM2 transcripts was detected in mycorrhizal roots relative to noninoculated roots. C, OsRAM2L expression in the roots, stems, and leaves of AM-colonized (AM+) or noncolonized (AM-) plants at 6 wpi. Expression levels were normalized to the geometric mean of housekeeping gene OsCyclophilin2 (B and C). The RNA was extracted from three individual plants. Error bars represent standard deviation $(n=3$, where $n$ denotes the number of technical repetition). Asterisks indicate significant difference (Student's $t$ test; $*$ and ${ }^{* *}$ indicate $P<0.05$ and 0.01 , respectively; ns $=$ not significant).
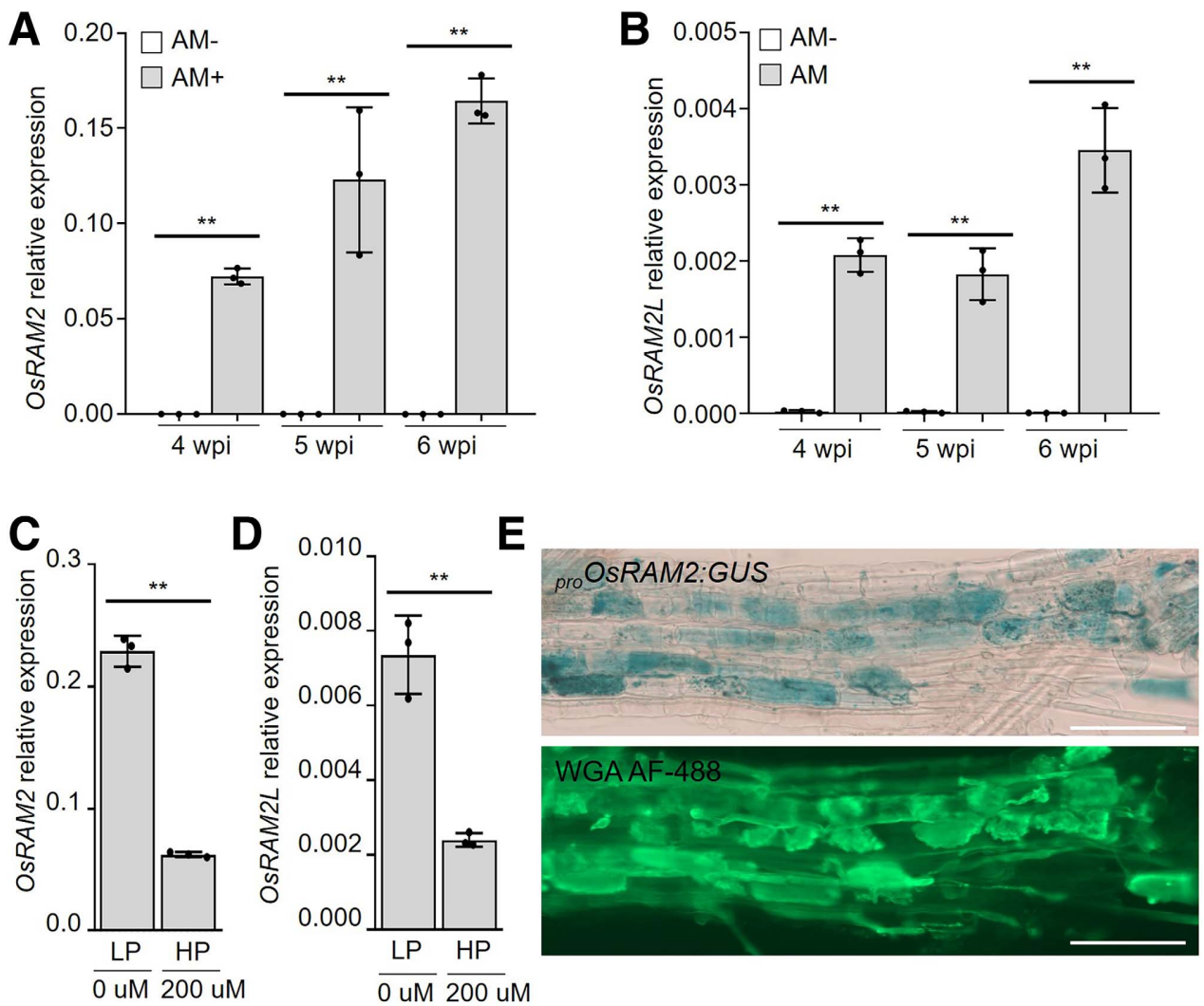

Fig. 2. OsRAM2 is exclusively expressed in rice arbusculated cells. A, OsRAM2 gene expression is induced in roots colonized by Rhizophagus irregularis compared with mock-inoculated roots (white bars). Plants were harvested 4, 5, and 6 weeks postinoculation (wpi). OsRAM2 gene expression increases over time. B, OsRAM2L gene expression in $R$. irregularis-colonized and mock-inoculated roots over time. Low phosphate $\left(\mathrm{LP}, 0 \mu \mathrm{M} \mathrm{KH} \mathrm{KO}_{4}\right)$ increases expression of $\mathbf{C}, O s R A M 2$ and $\mathbf{D}, O s R A M 2 L$ in arbuscular mycorrhizal (AM) symbiosis; high phosphate (HP, $\left.200 \mu \mathrm{M} \mathrm{KH}_{2} \mathrm{PO}_{4}\right)$ reduces this induction. Expression levels were normalized to the geometric mean of housekeeping gene OsCyclophilin2 (A to D). The RNA was extracted from three individual plants. Error bars represent standard deviation $(n=3$, where $n$ denotes the number of technical repetition). Asterisks indicate significant difference (Student's $t$ test; * and ** indicate $P<0.05$ and 0.01, respectively; ns = not significant). E, Bright field (upper panel) and corresponding WGA AF-488-stained (bottom panel) images of rice roots colonized with $R$. irregularis reveals $\beta$-glucuronidase staining in cortical arbuscular cells driven by the $O s R A M 2$ promoter. Bar $=50 \mu \mathrm{m}$. 
were reduced to less than 10 and $20 \%$ of WT levels in both AM-colonized and mock-inoculated Osraml mutant roots, respectively (Fig. 5A to D) and increased up to 30- to 50-fold in AM-colonized roots overexpressing OsRAM1 (Fig. 5B and D). The increase in $O S R A M 2$ and $O S R A M 2 L$ expression was proportionally much higher than the increase of mycorrhizal colonization in the same roots (Supplementary Fig. S3), indicating that OsRAM1 regulation of OSRAM2 expression is only partly correlated with mycorrhizal colonization.

In L. japonicus, CYCLOPS, a CSSP protein which forms a complex with CCaMK and DELLA, directly regulates RAMI expression through association with an $A M C Y C-R E$ cis-element in its promoter (Pimprikar et al. 2016). In order to check whether the OsRAM2 expression pattern relies on CSSP genes, we analyzed OsRAM2 and OsRAM2L expression in ccamk-2 and cyclops-3 mutants, which have defects in cortical mycorrhizal colonization (Supplementary Fig. S3) (Gutjahr et al. 2008). The transcripts of OsRAM2 and OsRAM2L were reduced to less than 1 and $15 \%$ of WT levels in ccamk- 2 and cyclops- 3 mutants, respectively, in AM-colonized plants (Fig. 5B and D). These results support the notion that $O s R A M 2$ and $O s R A M 2 L$ function downstream of CSSP components.
A

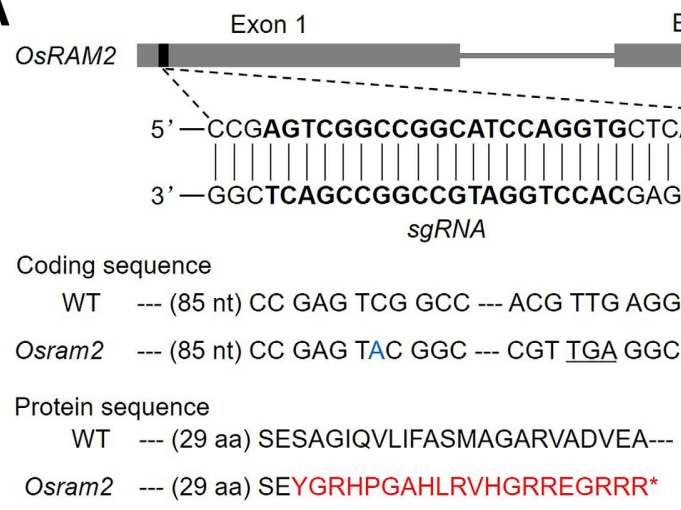

Exon 2

B

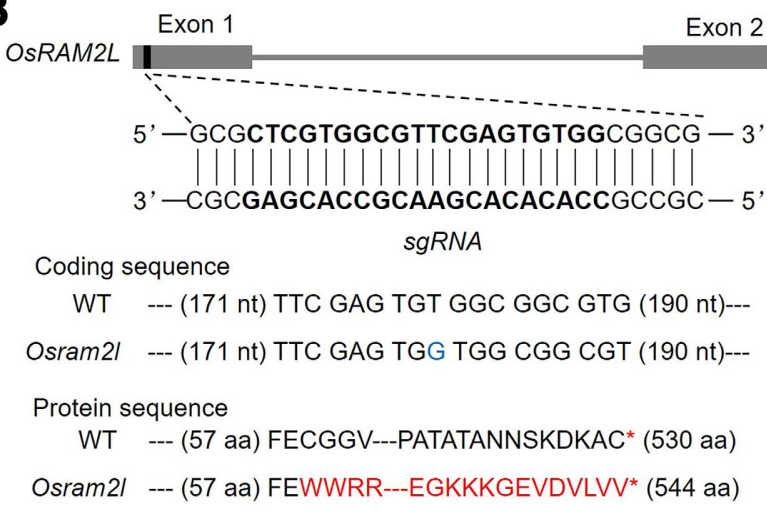

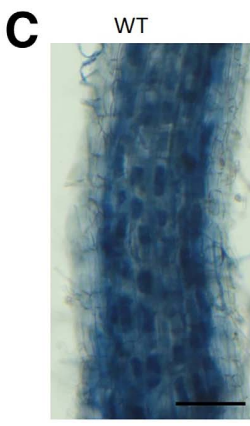
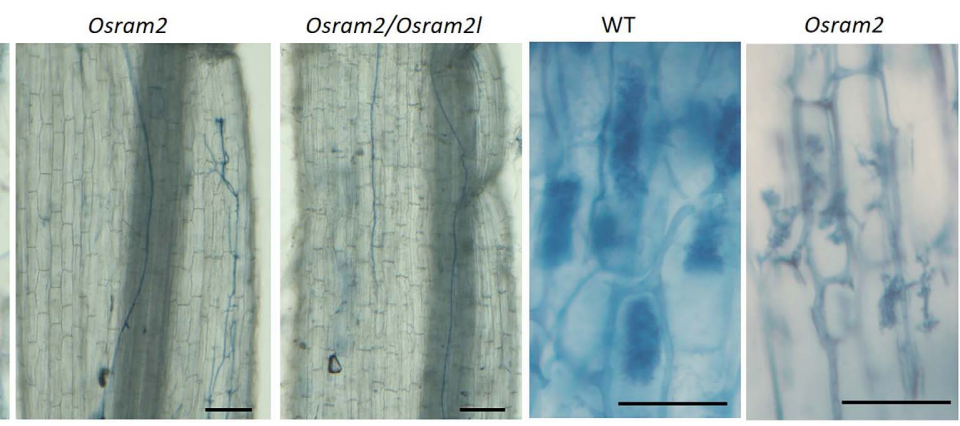

Osram2/Osram21
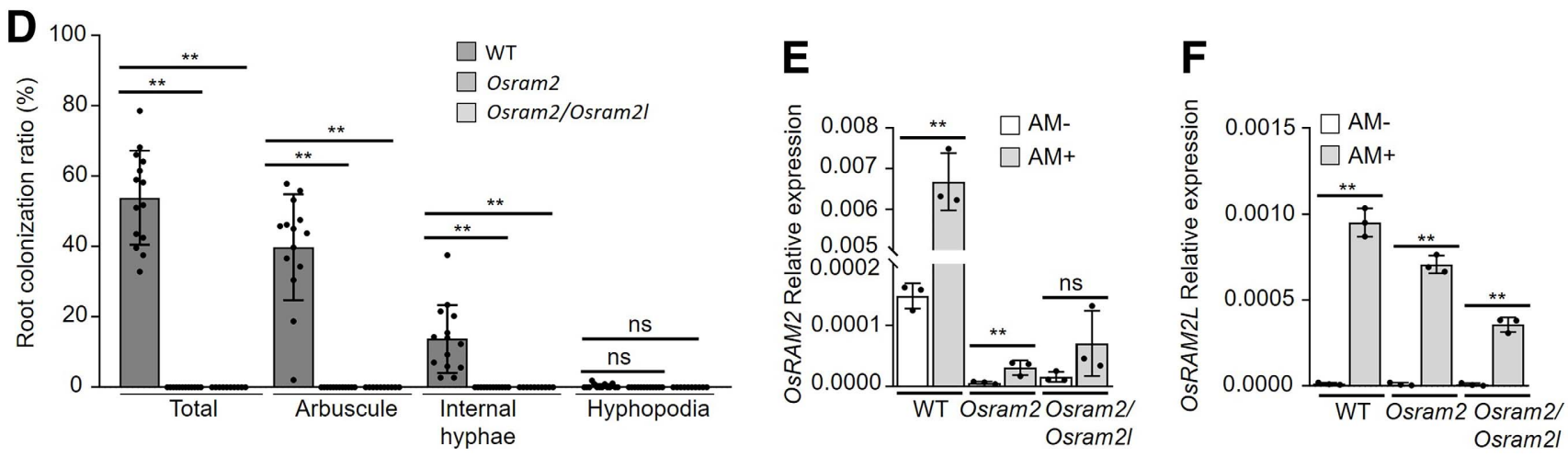

Fig. 3. Mycorrhizal colonization is impaired in Osram 2 and Osram $2 / O s r a m 2 L$ mutants. DNA alignments of $O s R A M 2$ or $O s R A M 2 L$ and corresponding coding and protein sequences for A, Osram 2 and B, Osram $2 l$ mutants and wild-type (WT) plants. Target sequences of the guide RNAs are indicated in bold. CRISPR/Cas9-induced insertions are labeled in blue. Numbers indicate nucleotide or protein position in the WT sequence. Single-nucleotide insertion results (blue) in a frameshift (red) and premature stop codon (red asterisk) in OsRAM2 (A) and protein sequence alteration in $O s R A M 2 L$ (B). C, Trypan blue staining of the fungus to reveal the arbuscule morphology in WT, Osram2, and Osram2/Osram2l roots colonized by Rhizophagus irregularis. Scale bar = $100 \mu \mathrm{m}$. D, Quantification of $R$. irregularis root-length colonization in WT, Osram2, and Osram2/Osram2l roots. Bar graphs show the mean, with error bars representing standard deviation The experiment was repeated three times with similar results. Each plant analyzed is plotted as a black dot. Asterisks indicate significant difference (Student's $t$ test; $*$ and $* *$ indicate $P<0.05$ and 0.01 , respectively; ns = not significant). E, OsRAM2 expression is induced after arbuscular mycorrhizal (AM) inoculation and decreased in Osram2 mutants. F, OsRAM2L expression is obviously upregulated upon AM inoculation but the expression level is reduced in Osram 2 and Osram2/Osram $2 L$ mutants. Expression levels were normalized to the geometric mean of housekeeping gene OsCyclophilin2 (E and F). The RNA was extracted from three individual plants of WT or mutants. Error bars represent standard deviation ( $n=3$, where $n$ denotes the number of technical repetition). Asterisks indicate significant difference (Student's $t$ test; ${ }^{*}$ and $* *$ indicate $P<0.05$ and 0.01 , respectively; ns $=$ not significant). 
OsRAM2/OsRAM2L participate

in Magnaporthe oryzae infection.

Considering the similarities in the signaling events and morphological changes that occur inside host cells during infection of the biotrophic pathogen of Magnaporthe oryzae and colonization by mycorrhizal fungi (He et al. 2019; Marcel et al. 2010; Paszkowski. 2006; Sesma and Osbourn. 2004; Zhang et al. 2015; Zhang et al. 2021), we assayed whether OsRAM2 plays a role in the plant $-M$. oryzae interaction. Interestingly, we found that OsRAM2 was dramatically induced upon infection by $M$. oryzae (Fig. 6A and B), implying that OsRAM2 participates in $M$. oryzae colonization of rice roots. $M$. oryzae typically invades plant roots, although it is a more severe pathogen in rice leaves (Marcel et al. 2010; Sesma and Osbourn. 2004; Zhang et al. 2021). We inoculated rice roots with $M$. oryzae and measured infected lesion size in the WT and Osram 2 and Osram $2 / O s r a m 2 l$ mutants. We observed obvious pathogen-induced browning and root growth inhibition in the WT at 2 wpi (Fig. 6C). Intriguingly, the growth of the WT roots was severely impaired upon $M$. oryzae invasion, whereas the root lengths of Osram 2 and Osram2/Osram $2 l$ mutants were only slightly affected (Fig. 6D). The length of noninoculated Osram 2 and Osram $2 / O$ sram $2 l$ mutants roots was comparable with that of the WT (Fig. 6C; Supplementary Fig. S4). In addition, the infection ratio, which represents the ratio of lesion length to root length, was lower in Osram 2 and Osram2/Osram $2 l$ mutant roots (Fig. 6E). Consistent with this, the relative fungal growth biomass reflecting the amount of fungus on the roots was also lower in Osram 2 and Osram $2 / O s r a m 2 l$ mutant roots than in those of the WT (Fig. 6F), as revealed by the ratio of expression of M. oryzae Pot 2 versus rice ubiquitin (Zhang et al. 2021).

We also found higher expression of the defense marker OsCHITINASE in infected Osram2 and Osram2/Osram $2 l$ mutants compared with infected WT roots, while OsPR10 was slightly upregulated in Osram $2 / O$ sram $2 l$-colonized roots (Fig. $6 \mathrm{G}$ and $\mathrm{H})$. In summary, enhanced defense-related signaling appears to have suppressed the invasion of rice blast in Osram 2
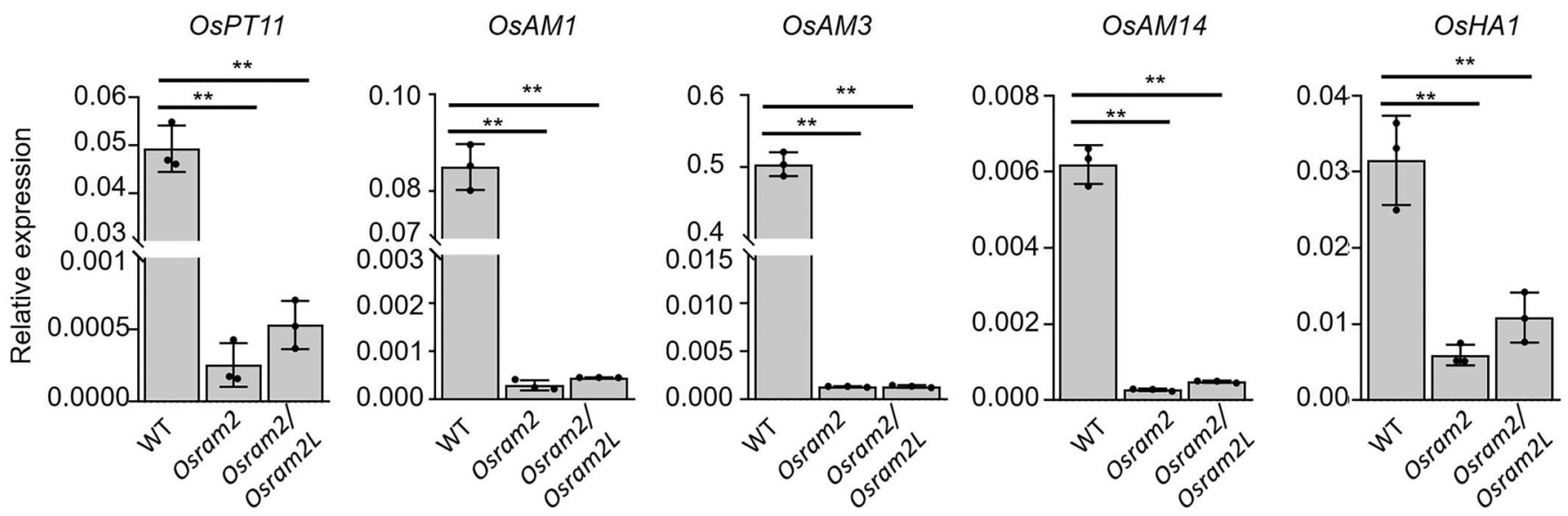

Fig. 4. Expression of arbuscular mycorrhizal (AM) marker genes. AM marker genes including OsPT11, OsAM1, OsAM3, OsAM14, and OsHA1 decreased expression in Osram 2 and Osram $2 / O \operatorname{sram} 2 L$ mutants compared with that in the wild type (WT) upon mycorrhizal colonization. Expression levels were normalized to the geometric mean of housekeeping gene OsCyclophilin2. The RNA was extracted from three individual plants of WT or mutants. The experiment was repeated three times with similar results. Error bars represent standard deviation $(n=3$, where $n$ denotes the number of technical repetition). Asterisks indicate significant difference (Student's $t$ test; ${ }^{*}$ and ${ }^{* *}$ indicate $P<0.05$ and 0.01 , respectively; ns $=$ not significant).

A

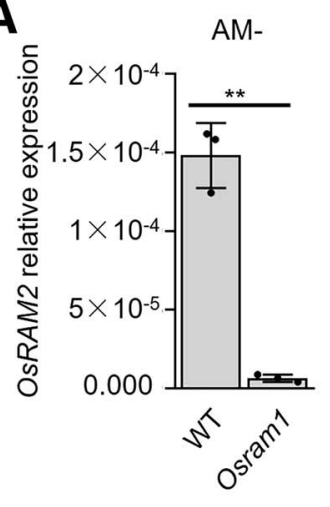

B

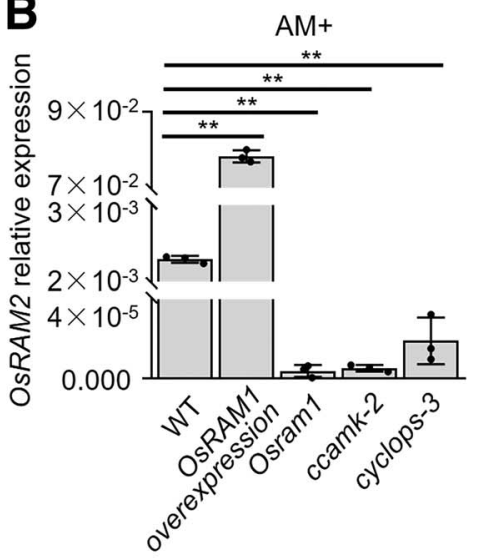

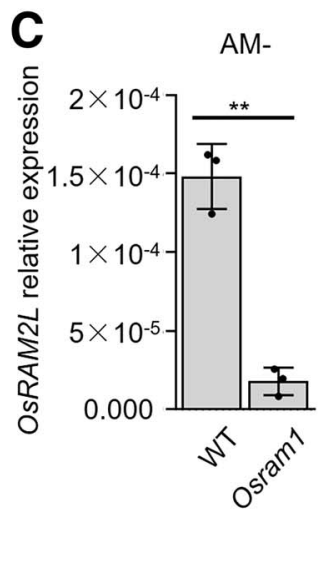

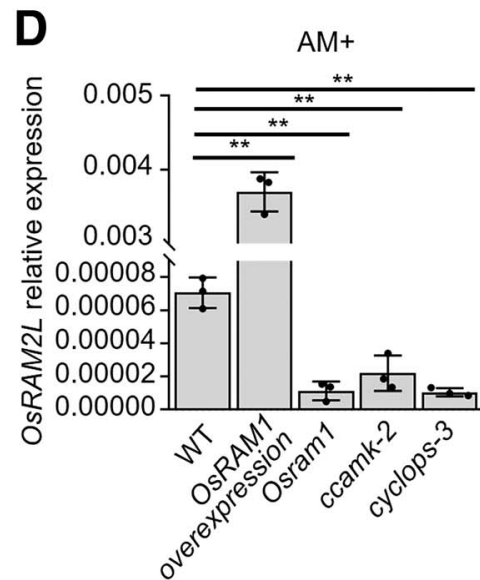

Fig. 5. Expression of $O S R A M 2$ and $O S R A M 2 L$ is dependent on common symbiosis signaling pathway. A, Transcript level of $O s R A M 2$ is reduced in the noninoculated Osram 1 mutant roots. B, OsRAM2 displays induced expression in the OsRAM1 overexpression roots during arbuscular mycorrhizal (AM) symbiosis. In Osram1, ccamk-2, and cyclops-3 roots, the induction of OsRAM2 by AM inoculation is decreased relative to the AM-colonized wild type (WT). C, Transcript level of $O s R A M 2 L$ is reduced in the noninoculated Osram 1 mutant roots, reminiscent of $O s R A M 2$. D, OsRAM2L is induced in symbiosis and OsRAM1 overexpression facilitates $O s R A M 2 L$ expression. Expression of OsRAM2L is almost abolished in Osram1, ccamk-2, and cyclops-3 roots. Expression levels were normalized to the geometric mean of housekeeping gene OsCyclophilin2 (A to D). The RNA was extracted from three individual plants of the WT or mutants. Error bars represent standard deviation $(n=3$, where $n$ denotes the number of technical repetition). Asterisks indicate significant difference (Student's $t$ test; $*$ and $* *$ indicate $P<0.05$ and 0.01 , respectively; ns $=$ not significant). 
and Osram $2 / O$ sram $2 l$ mutants. In addition to this, CSSP gene mutants, including ccamk-2 and cyclops-3 roots, did not show altered response to fungal inoculation compared with WT plants (Supplementary Fig. S5), indicating that OsRAM2's participation in the $M$. oryzae infection process is independent of CSSP components.

\section{DISCUSSION}

AM fungi are characterized as fatty acid auxotrophs due to the lack of fatty acid synthase genes in the genome. Several studies showed that host-derived fatty acids are directly delivered to the AM fungi (Bravo et al. 2017; Jiang et al. 2017; Keymer et al. 2017; Luginbuehl et al. 2017). With the addition of the fatty acids myristate and palmitate to the media, AM fungi were able to grow extensively and produce infection-competent secondary spores in the absence of a host plant (Kameoka et al. 2019; Sugiura et al. 2020), further supporting the importance of fatty acids as an energy source for fungal growth. In legumes, $R A M 2$ is required for the accumulation of fatty acids in mycorrhizal roots, which are then likely transferred to the fungi by STR and STR2 (Bravo et al. 2017; Jiang et al. 2017, 2018; Wang et al. 2012). Here, we show that the rice RAM2 homolog OsRAM2 was exclusively expressed in arbuscular cells, and both Osram 2 and Osram2/Osram $2 l$ displayed defects in mycorrhizal infection and arbuscule development, indicating that OsRAM2-mediated fatty acid biosynthesis is important for mycorrhizal colonization in rice. Osram 2 and Osram $2 / O s r a m 2 l$ double mutants also showed less severe $M$. oryzae infection; thus, OsRAM2 plays an important role in both AM symbiosis and pathogen colonization, and this role is conserved in dicotyledon and monocotyledon plants and OSRAM2 is a potential target to restrain $M$. oryzae infection in agriculture.

$O s R A M 2$ and $O S R A M 2 L$ showed decreased expression in the mycorrhiza-colonized roots of CSSP gene ccamk-2 and cyclops3 mutants, indicating that OsRAM2 and OsRAM2L might act downstream of CSSP in response to symbiotic fungi. Furthermore, we showed that the transcript levels of OsRAM2 and OsRAM $2 L$ decreased in the Osram 1 mutant. In addition, overexpressing OsRAM1 can active expression of OsRAM2 and OsRAM2L, consistent with what was reported in B. distachyon (Müller et al. 2020). Thus, the regulation of RAM2 by RAM1 is conserved in rice, Medicago truncatula, and $B$. distachyon (Gobbato et al. 2012, 2013; Müller et al. 2020; Wang et al. 2012).

In addition to symbionts, the phytopathogenic fungus Golovinomyces cichoracerum also recruits the fatty acid biosynthesis program during invasion, as indicated by the increased levels of fatty acids and reduced fungal invasion in Arabidopsis leaves of fatty acid biosynthetic gene mutants (Jiang et al. 2017). In $M$. truncatula, the oomycete pathogen Phytophthora palmivora can barely form appressoria in ram2 roots (Wang et al. 2012). In contrast to AM fungi, the genes involved in fatty acid biosynthesis are present in the genomes of G. cichoracerum, Phytophthora spp., and Magnaporthe oryzae (bin Yusof et al. 2014; Liang et al. 2018; Rodenburg et al. 2018), suggesting that host lipids could serve as an alternative energy source for these parasites (Liang et al. 2018). In this study, we found that OsRAM2 is induced in roots colonized by $M$. oryzae. Interestingly, the fatty acid biosynthesis genes including pyruvate kinase (OsPK, LOC_Os01g47080) and ketoacyl-acyl carrier protein reductase
A

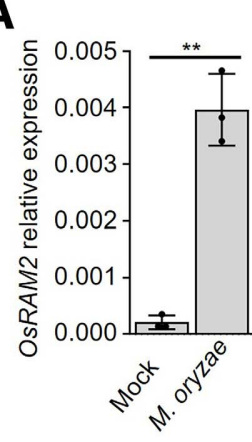

E

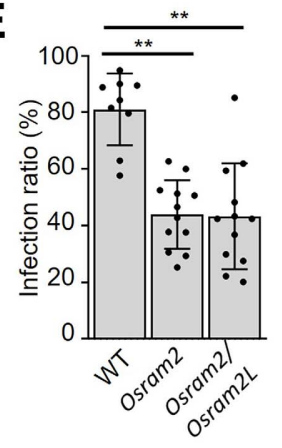

B

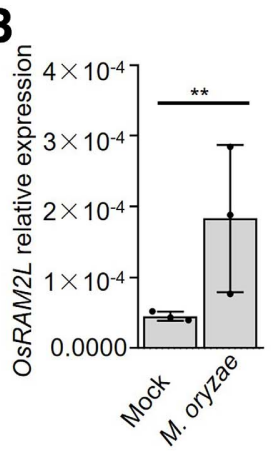

$\mathbf{F}$

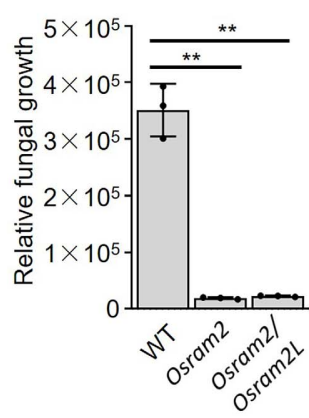

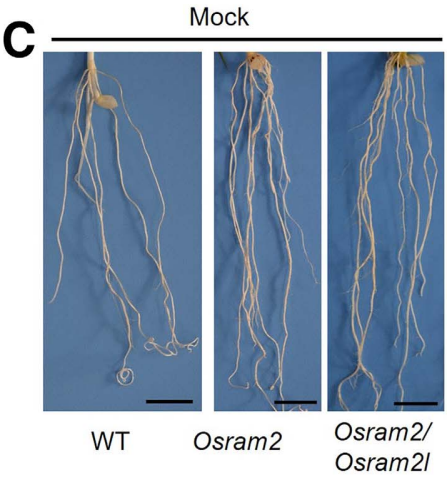

G

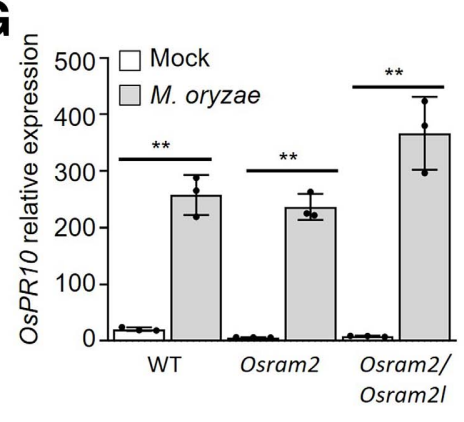

M. oryzae
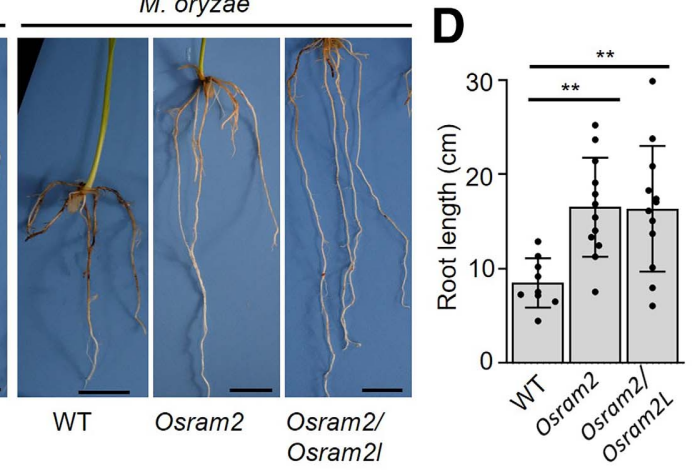

$\mathbf{H}$

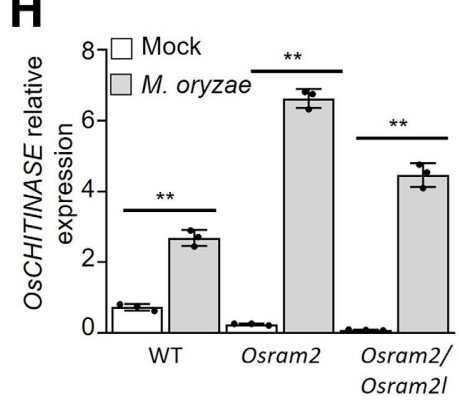

Fig. 6. OsRAM2 participates in Magnaporthe oryzae colonization. A and B, OsRAM2 and OsRAM2L expression upon M. oryzae infection. C, Growth phenotype of $M$. oryzae-inoculated and noninoculated rice roots. Infection of rice blast fungal pathogen in Osram 2 and $O s r a m 2 / O s r a m 2 l$ roots was weaker than that in the wild type (WT). Lesions were photographed at 2 weeks postinoculation (wpi). The experiment was repeated three times and showed the same result. Bar $=10 \mathrm{~mm}$. D, Root length of Osram2, Osram2/Osram $2 l$, and WT at 2 wpi. E, Disease resistance to rice blast in Osram 2 , Osram $2 / O s r a m 2 l$, and WT, measured by the ratio of lesion length to root length. F, Disease resistance to rice blast in $O s r a m 2$, Osram $2 / O s r a m 2 l$, and WT, measured by relative fungal growth. G and H, Relative expressions of defense-related marker genes OsPR10 and OsCHITINASE in Osram2, Osram $2 / O s r a m 2 l$, and WT roots at 2 wpi by real-time PCR. Expression levels were normalized to the geometric mean of housekeeping gene OsCyclophilin2 (A, B, G, and H). The RNA was extracted from three individual plants of the WT or mutants. Error bars represent standard deviation $(n=3$, where $n$ denotes the number of technical repetition). The experiment was repeated three times with similar results. Asterisks indicate significant difference (Student's $t$ test; ${ }^{*}$ and $* *$ indicate $P<0.05$ and 0.01 , respectively; ns $=$ not significant). 
(OsKAR, LOC_Os12g13930) was upregulated by M. oryzae infection (Supplementary Fig. S6). Rice roots lacking OsRAM2 showed more resistance to rice blast fungi, reminiscent of Mtram2 resistance to an oomycete pathogen infection in Medicago truncatula, suggesting that the fatty acid program is also recruited by parasitic pathogen in monocotyledon plants.

Interestingly, it has been reported that Magnaporthe oryzae might use an invasion strategy similar to that of mycorrhizal fungi in plant roots (Marcel et al. 2010). However, ccamk-2 and cyclops-3 showed WT levels of resistance to M. oryzae (Supplementary Fig. S5). The same results were also observed in dmi3 (homolog of $C C a M K$ ) mutants in Medicago truncatula inoculated by P. palmivora (Rey et al. 2015). These different lines of evidence suggest that $R A M 2$ is regulated separately in response to symbiosis and pathogenic fungi in both monocots and dicots. However, the mechanisms underlying its regulation in phytopathogen invasion requires further exploration.

\section{MATERIALS AND METHODS}

Plant material and growth conditions.

$O$. sativa subsp. japonica 'Nipponbare' was used as the WT for the Osram2, Osram2/Osram2l, Osram1, ccamk-2, and cyclops-3 mutants, as well as the OsRAM1 overexpression rice line. Osram 2 and Osram $2 l$ mutants were generated using the CRISPR-CAS9 mediated editing methods in Nipponbare (He et al. 2019). The Osram $2 / O s r a m 2 l$ double mutant line was generated by crossing Osram 2 and Osram $2 l$ plants. The alleles of ccamk and cyclops mutants were ccamk-2 and cyclops-3, kindly provided by professor Uta Paszkowski (Gutjahr et al. 2008). Osraml mutants were reported previously (Shi et al. 2021).

\section{Plant growth and Rhizophagus irregularis inoculation.}

Rice seeds were surface sterilized with $75 \%$ ethyl alcohol for $1 \mathrm{~min}$ and $25 \%$ sodium hypochlorite for $30 \mathrm{~min}$, followed by five washes with sterile water. The seeds were then transferred to half-strength Murashige and Skoog (1/2 MS) medium. Healthy seedlings were transplanted into a vermiculite, sand, and perlite (3:1:1) mixture containing Rhizophagus irregularis spores and cultured in a greenhouse at $28^{\circ} \mathrm{C}$ under conditions of $16 \mathrm{~h}$ of light and $8 \mathrm{~h}$ of darkness. The spores were produced by an $R$. irregularis-leek coculture and diluted to a final concentration of 400 spores/plant (Zhang et al. 2021). For phosphate treatment, $10 \mathrm{ml}$ of Hoagland solution with $0 \mu \mathrm{M}$

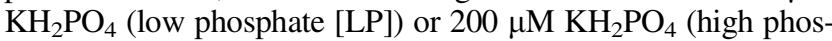
phate [HP]) were applied to the plants every 2 days from the third week until harvest. When the rice plants were inoculated with $R$. irregularis in the substrate (vermiculite, sand, and perlite [3:1:1] mixture), proper amounts of water were supplied in the first 2 weeks for plant growth. Subsequently, $10 \mathrm{ml}$ of Hoagland solution with $0 \mu \mathrm{M} \mathrm{KH}_{2} \mathrm{PO}_{4}$ (LP) or $200 \mu \mathrm{M}$ $\mathrm{KH}_{2} \mathrm{PO}_{4}(\mathrm{HP})$ were applied to the plants every 2 days from the third week until harvest.

\section{Root staining and mycorrhizal colonization quantification.}

For quantification of arbuscular mycorrhizal colonization, arbuscular mycorrhizal fungi colonized roots were stained with ink as follows: $10 \% \mathrm{KOH}$ for $12 \mathrm{~min}$ at $95^{\circ} \mathrm{C}$, rinsing by water, and staining with ink for $6 \mathrm{~min}$ at $95^{\circ} \mathrm{C}$. The mycorrhizal colonization level was examined and quantified using a gridline intersect method, as described previously (Zhang et al. 2015); each point represented a single plant. For arbuscules structure images, mycorrhizal fungi-colonized roots were stained with trypan blue as follows: $10 \% \mathrm{KOH}$ for $30 \mathrm{~min}$ at $90^{\circ} \mathrm{C}, 10 \% \mathrm{H}_{2} \mathrm{O}_{2}$ for $10 \mathrm{~min}$ at room temperature, and staining with trypan blue for $20 \mathrm{~min}$ at $90^{\circ} \mathrm{C}$. Images were taken using a Zesis Axio Scope A1 microscope.
Rice blast infection assay.

Magnaporthe oryzae root infections were carried out as previously described (Zhang et al. 2021). M. oryzae cultures for root infection assays were grown on potato dextrose agar for 8 days at $22^{\circ} \mathrm{C}$, and mycelial plugs were taken from the colony margin. The diameter of mycelial plugs was slightly smaller than the tubes to be used later. The 50 -ml plastic centrifuge tubes were filled with $35 \mathrm{ml}$ of sterile vermiculite containing $10 \mathrm{ml}$ of sterile water. The mycelial plug was placed on top of this and covered with a further $5 \mathrm{ml}$ of vermiculite. Mock-inoculated tubes were placed with sterile agar plugs. Three surface-sterilized seeds were placed on top of the second vermiculite layer, followed by an additional $5 \mathrm{ml}$ of vermiculite and $5 \mathrm{ml}$ of sterile water. Five replicate tubes were set up for each treatment. Tubes were covered with the covers and incubated at $28^{\circ} \mathrm{C}$ under conditions of $16 \mathrm{~h}$ of light and $8 \mathrm{~h}$ of darkness for 2 to 3 weeks. The seedling roots were then washed in water and measured for lesions using a ruler.

\section{Measurement of relative fungal growth.}

In total, 2-cm infected roots centered on the lesion were cut, and total DNA was extracted using a cetyltrimethylammonium bromide method (Zhang et al. 2021). The relative expression of the M. oryzae Pot 2 gene and the rice ubiquitin gene were measured by real-time PCR. The primer sequences for Pot 2 and ubiquitin and the formula for computing relative fungal growth were previously described (Zhang et al. 2021).

\section{Histochemical GUS analysis.}

The AM fungi colonized transgenic plant roots were soaked in the GUS staining buffer (10 mM EDTA, $100 \mathrm{mM} \mathrm{NaH}$ $\mathrm{PO}_{4} \cdot \mathrm{H}_{2} \mathrm{O}, 0.5 \mathrm{mM} \mathrm{K} \mathrm{K}_{4} \mathrm{Fe}(\mathrm{CN})_{6} \cdot 3 \mathrm{H}_{2} \mathrm{O}, \mathrm{K}_{3} \mathrm{Fe}(\mathrm{CN})_{6}, 0.1 \%$ Triton $\mathrm{X}-100$ and $0.5 \mathrm{mM} \mathrm{X}$-Gluc) follow by a vacuum treatment for 30 $\mathrm{min}$. The root samples were then incubated at $37^{\circ} \mathrm{C}$ overnight. The staining was terminated by immersing the root samples in 50\% ethanol. Then the plants carrying proOsRAM2:GUS were immersed into $1 \times$ phosphate buffered saline solution containing $0.2 \mu \mathrm{g} / \mathrm{ml}$ WGA-Alexa Fluor 488 overnight for WGA staining. Images of roots stained with WGA-Alexa Fluor 488 (Yu et al. 2014) were taken with a Zesis Axio Scope A1 microscope.

\section{Plasmid construction and rice transformation.}

For gene editing in rice, target sequences were selected using the CRISPR website. For single-gene editing, the target sequences were synthesized and inserted into the subgenomic RNA through the $B s a \mathrm{I}$ site and then cloned into the Ph-Ubi-cas9-7 vector using the LR recombination reaction. For promoter analysis, 3-kb OSRAM2 promoters were cloned into the modified plasmid pCAMBIA1300-GUS using SalI and BamHI. For OsRAMI overexpression in rice, the full-length cDNA of $O s R A M 1$ without the stop codon was cloned into pDONR207, then inserted into pCambia1301 by LR recombination. The constructs were introduced into Agrobacterium strain EHA105 and transferred to Nipponbare as described previously (Zhang et al. 2015). Primers used for cloning are listed in Supplementary Table S1.

\section{RNA extraction and gene expression.}

For quantitative real-time PCR (qRT-PCR), each biological replicate comprised three individual roots. Total RNA was extracted from $100 \mathrm{mg}$ of well-ground root tissue of each sample using Trizol reagent. Reverse transcription was carried out with $1 \mu \mathrm{g}$ of total RNA by using the PrimeScript RT Reagent Kit (Takara Bio) according to the manufacturer's instruction. qRT-PCR was performed using a Bio-Rad CFX Connect realtime detection system and the SYBR Green Premix Ex Taq (Takara Bio). For the gene expression analysis, the relative transcript levels of three technical repeats per sample were 
normalized to the geometric mean of amplification of housekeeping genes OsCyclophilin2 (LOC_Os02g02890) and $2^{-\triangle \mathrm{Ct}}$ was used to analyze the data. The presented data are from three independent biological repeats. Sequences of real-time PCR primers are given in Supplementary Table S1.

\section{Phylogenetic analyses.}

MtRAM2 was used as query to identify its orthologs in Medicago truncatula, Glycine max, O. sativa, and Arabidopsis thaliana with BLASTP with standard parameters in phytozome V13 and the rice genome annotation project. The homologs with protein identity higher than $55 \%$ were selected. All of the amino acid sequences were aligned using MEGA-X. The phylogenetic tree was constructed using the maximum-likelihood method in MEGA-X with 1,000 bootstrap repetitions. The other parameters are default.

\section{AUTHOR-RECOMMENDED INTERNET RESOURCES}

CRISPR website: http://crispr.hzau.edu.cn/CRISPR2/

phytozome V13: https://phytozome-next.jgi.doe.gov/pz/portal.html Rice genome annotation project: http://rice.uga.edu/

RiceXPro: https://ricexpro.dna.affrc.go.jp/

\section{LITERATURE CITED}

Akiyama, K., Matsuzaki, K., and Hayashi, H. 2005. Plant sesquiterpenes induce hyphal branching in arbuscular mycorrhizal fungi. Nature 435: 824-827.

Besserer, A., Puech-Pagès, V., Kiefer, P., Gomez-Roldan, V., Jauneau, A., Roy, S., Portais, J. C., Roux, C., Bécard, G., and Séjalon-Delmas, N. 2006. Strigolactones stimulate arbuscular mycorrhizal fungi by activating mitochondria. PLoS Biol. 4:e226.

bin Yusof, M. T., Kershaw, M. J., Soanes, D. M., and Talbot, N. J. 2014 FAR1 and FAR2 regulate the expression of genes associated with lipid metabolism in the rice blast fungus Magnaporthe oryzae. PloS One 9: e99760.

Bravo, A., Brands, M., Wewer, V., Dörmann, P., and Harrison, M. J 2017. Arbuscular mycorrhiza-specific enzymes FatM and RAM2 finetune lipid biosynthesis to promote development of arbuscular mycorrhiza. New Phytol. 214:1631-1645.

Brundrett, M. C., and Tedersoo, L. 2018. Evolutionary history of mycorrhizal symbioses and global host plant diversity. New Phytol. 220: 1108-1115.

Chiu, C. H., and Paszkowski, U. 2019. Mechanisms and impact of symbiotic phosphate acquisition. Cold Spring Harb. Perspect. Biol. 11: a034603.

Choi, J., Summers, W., and Paszkowski, U. 2018. Mechanisms underlying establishment of arbuscular mycorrhizal symbioses. Annu. Rev. Phytopathol. 56:135-160.

Floss, D. S., Levy, J. G., Lévesque-Tremblay, V., Pumplin, N., and Harrison, M. J. 2013. DELLA proteins regulate arbuscule formation in arbuscular mycorrhizal symbiosis. Proc. Natl. Acad. Sci. U.S.A. 110: E5025-E5034.

Foo, E., Ross, J. J., Jones, W. T., and Reid, J. B. 2013. Plant hormones in arbuscular mycorrhizal symbioses: An emerging role for gibberellins. Ann. Bot. 111:769-779.

Genre, A., Chabaud, M., Balzergue, C., Puech-Pagès, V., Novero, M., Rey, T., Fournier, J., Rochange, S., Bécard, G., Bonfante, P., and Barker, D. G. 2013. Short-chain chitin oligomers from arbuscular mycorrhizal fungi trigger nuclear $\mathrm{Ca}^{2+}$ spiking in Medicago truncatula roots and their production is enhanced by strigolactone. New Phytol. 198:190-202

Genre, A., Chabaud, M., Faccio, A., Barker, D. G., and Bonfante, P. 2008. Prepenetration apparatus assembly precedes and predicts the colonization patterns of arbuscular mycorrhizal fungi within the root cortex of both Medicago truncatula and Daucus carota. Plant Cell 20: 1407-1420.

Genre, A., Chabaud, M., Timmers, T., Bonfante, P., and Barker, D. G. 2005. Arbuscular mycorrhizal fungi elicit a novel intracellular apparatus in Medicago truncatula root epidermal cells before infection. Plant Cell 17:3489-3499.

Genre, A., Lanfranco, L., Perotto, S., and Bonfante, P. 2020. Unique and common traits in mycorrhizal symbioses. Nat. Rev. Microbiol. 18: 649-660.
Gobbato, E., Marsh, J. F., Vernié, T., Wang, E., Maillet, F., Kim, J., Miller, J. B., Sun, J., Bano, S. A., Ratet, P., Mysore, K. S., Dénarié, J., Schultze, M., and Oldroyd, G. E. 2012. A GRAS-type transcription factor with a specific function in mycorrhizal signaling. Curr. Biol. 22: 2236-2241.

Gobbato, E., Wang, E., Higgins, G., Bano, S. A., Henry, C., Schultze, M., and Oldroyd, G. E. D. 2013. RAM1 and RAM2 function and expression during arbuscular mycorrhizal symbiosis and Aphanomyces euteiches colonization. Plant Signal. Behav. 8:e26049.

Graham, J. H., Drouillard, D. L., and Hodge, N. C. 1996. Carbon economy of sour orange in response to different Glomus spp. Tree Physiol. 16:1023-1029.

Gutjahr, C., Banba, M., Croset, V., An, K., Miyao, A., An, G., Hirochika, H., Imaizumi-Anraku, H., and Paszkowski, U. 2008. Arbuscular mycorrhiza-specific signaling in rice transcends the common symbiosis signaling pathway. Plant Cell 20:2989-3005

Gutjahr, C., and Parniske, M. 2013. Cell and developmental biology of arbuscular mycorrhiza symbiosis. Annu. Rev. Cell Dev. Biol. 29:593617.

Gutjahr, C., Radovanovic, D., Geoffroy, J., Zhang, Q., Siegler, H., Chiapello, M., Casieri, L., An, K., An, G., Guiderdoni, E., Kumar, C. S., Sundaresan, V., Harrison, M. J., and Paszkowski, U. 2012. The half-size ABC transporters STR1 and STR2 are indispensable for mycorrhizal arbuscule formation in rice. Plant J. 69:906-920.

He, J., Zhang, C., Dai, H., Liu, H., Zhang, X., Yang, J., Chen, X., Zhu, Y., Wang, D., Qi, X., Li, W., Wang, Z., An, G., Yu, N., He, Z., Wang, Y. F., Xiao, Y., Zhang, P., and Wang, E. 2019. A LysM receptor heteromer mediates perception of arbuscular mycorrhizal symbiotic signal in rice. Mol. Plant 12:1561-1576.

Horváth, B., Yeun, L. H., Domonkos, A., Halász, G., Gobbato, E. Ayaydin, F., Miró, K., Hirsch, S., Sun, J., Tadege, M., Ratet, P., Mysore, K. S., Ané, J. M., Oldroyd, G. E., and Kaló, P. 2011. Medicago truncatula IPD3 is a member of the common symbiotic signaling pathway required for rhizobial and mycorrhizal symbioses. Mol. Plant-Microbe Interact. 24:1345-1358

Jiang, Y., Wang, W., Xie, Q., Liu, N., Liu, L., Wang, D., Zhang, X., Yang, C., Chen, X., Tang, D., and Wang, E. 2017. Plants transfer lipids to sustain colonization by mutualistic mycorrhizal and parasitic fungi. Science 356:1172-1175

Jiang, Y., Xie, Q., Wang, W., Yang, J., Zhang, X., Yu, N., Zhou, Y., and Wang, E. 2018. Medicago AP2-domain transcription factor WRI5a is a master regulator of lipid biosynthesis and transfer during mycorrhizal symbiosis. Mol. Plant 11:1344-1359.

Jin, Y., Liu, H., Luo, D., Yu, N., Dong, W., Wang, C., Zhang, X., Dai, H., Yang, J., and Wang, E. 2016. DELLA proteins are common components of symbiotic rhizobial and mycorrhizal signalling pathways Nat. Commun. 7:12433.

Kameoka, H., Tsutsui, I., Saito, K., Kikuchi, Y., Handa, Y., Ezawa, T., Hayashi, H., Kawaguchi, M., and Akiyama, K. 2019. Stimulation of asymbiotic sporulation in arbuscular mycorrhizal fungi by fatty acids. Nat. Microbiol. 4:1654-1660.

Keymer, A., Pimprikar, P., Wewer, V., Huber, C., Brands, M., Bucerius, S. L., Delaux, P. M., Klingl, V., Röpenack-Lahaye, E. V., Wang, T. L., Eisenreich, W., Dörmann, P., Parniske, M., and Gutjahr, C. 2017. Lipid transfer from plants to arbuscular mycorrhiza fungi. eLife 6:e29107.

Lévy, J., Bres, C., Geurts, R., Chalhoub, B., Kulikova, O., Duc, G., Journet, E. P., Ané, J. M., Lauber, E., Bisseling, T., Dénarié, J., Rosenberg, C., and Debellé, F. 2004. A putative $\mathrm{Ca}^{2+}$ and calmodulin-dependent protein kinase required for bacterial and fungal symbioses. Science 303:13611364

Liang, P., Liu, S., Xu, F., Jiang, S., Yan, J., He, Q., Liu, W., Lin, C., Zheng, F., Wang, X., and Miao, W. 2018. Powdery mildews are characterized by contracted carbohydrate metabolism and diverse effectors to adapt to obligate biotrophic lifestyle. Front. Microbiol. 9:3160.

Liu, J., Maldonado-Mendoza, I., Lopez-Meyer, M., Cheung, F., Town, C. D., and Harrison, M. J. 2007. Arbuscular mycorrhizal symbiosis is accompanied by local and systemic alterations in gene expression and an increase in disease resistance in the shoots. Plant J. 50:529-544.

Luginbuehl, L. H., Menard, G. N., Kurup, S., Van Erp, H., Radhakrishnan, G. V., Breakspear, A., Oldroyd, G. E. D., and Eastmond, P. J. 2017. Fatty acids in arbuscular mycorrhizal fungi are synthesized by the host plant. Science 356:1175-1178.

Maillet, F., Poinsot, V., André, O., Puech-Pagès, V., Haouy, A., Gueunier, M., Cromer, L., Giraudet, D., Formey, D., Niebel, A., Martinez, E. A., Driguez, H., Bécard, G., and Dénarié, J. 2011. Fungal lipochitooligosaccharide symbiotic signals in arbuscular mycorrhiza. Nature 469:58-63. 
Marcel, S., Sawers, R., Oakeley, E., Angliker, H., and Paszkowski, U. 2010. Tissue-adapted invasion strategies of the rice blast fungus Magnaporthe oryzae. Plant Cell 22:3177-3187.

Messinese, E., Mun, J. H., Yeun, L. H., Jayaraman, D., Rougé, P., Barre, A., Lougnon, G., Schornack, S., Bono, J. J., Cook, D. R., and Ané, J. M. 2007. A novel nuclear protein interacts with the symbiotic DMI3 calcium- and calmodulin-dependent protein kinase of Medicago truncatula. Mol. Plant-Microbe Interact. 20:912-921.

Müller, L. M., Campos-Soriano, L., Levesque-Tremblay, V., Bravo, A., Daniels, D. A., Pathak, S., Park, H. J., and Harrison, M. J. 2020. Constitutive overexpression of RAM1 leads to an increase in arbuscule density in Brachypodium distachyon. Plant Physiol. 184: 1263-1272.

Oldroyd, G. E. D. 2013. Speak, friend, and enter: Signalling systems that promote beneficial symbiotic associations in plants. Nat. Rev. Microbiol. 11:252-263.

Ovchinnikova, E., Journet, E. P., Chabaud, M., Cosson, V., Ratet, P., Duc, G., Fedorova, E., Liu, W., den Camp, R. O., Zhukov, V., Tikhonovich, I., Borisov, A., Bisseling, T., and Limpens, E. 2011. IPD3 controls the formation of nitrogen-fixing symbiosomes in pea and Medicago Spp. Mol. Plant-Microbe Interact. 24:1333-1344.

Park, H. J., Floss, D. S., Levesque-Tremblay, V., Bravo, A., and Harrison, M. J. 2015. Hyphal branching during arbuscule development requires reduced arbuscular mycorrhiza1. Plant Physiol. 169:27742788.

Parniske, M. 2008. Arbuscular mycorrhiza: The mother of plant root endosymbioses. Nat. Rev. Microbiol. 6:763-775.

Paszkowski, U. 2006. Mutualism and parasitism: The yin and yang of plant symbioses. Curr. Opin. Plant Biol. 9:364-370.

Pimprikar, P., Carbonnel, S., Paries, M., Katzer, K., Klingl, V., Bohmer, M. J., Karl, L., Floss, D. S., Harrison, M. J., Parniske, M., and Gutjahr, C. 2016. A CCaMK-CYCLOPS-DELLA complex activates transcription of RAM1 to regulate arbuscule branching. Curr. Biol. 26: 1126.

Rey, T., Chatterjee, A., Buttay, M., Toulotte, J., and Schornack, S. 2015. Medicago truncatula symbiosis mutants affected in the interaction with a biotrophic root pathogen. New Phytol. 206:497-500.

Rich, M. K., Schorderet, M., Bapaume, L., Falquet, L., Morel, P., Vandenbussche, M., and Reinhardt, D. 2015. The petunia GRAS transcription factor ATA/RAM1 regulates symbiotic gene expression and fungal morphogenesis in arbuscular mycorrhiza. Plant Physiol. 168: 788-797.

Rodenburg, S. Y. A., Seidl, M. F., de Ridder, D., and Govers, F. 2018. Genome-wide characterization of Phytophthora infestans metabolism: A systems biology approach. Mol. Plant Pathol. 19:1403-1413.

Sesma, A., and Osbourn, A. E. 2004. The rice leaf blast pathogen undergoes developmental processes typical of root-infecting fungi. Nature 431:582-586.

Shi, J., Zhao, B., Zheng, S., Zhang, X., Wang, X., Dong, W., Xie, Q., Wang, G., Xiao, Y., Chen, F., Yu, N., and Wang, E. 2021. A phosphate starvation response-centered network regulates mycorrhizal symbiosis. Cell 184:5527-5540.e18.
Singh, S., Katzer, K., Lambert, J., Cerri, M., and Parniske, M. 2014. CYCLOPS, a DNA-binding transcriptional activator, orchestrates symbiotic root nodule development. Cell Host Microbe 15:139-152.

Singh, S., and Parniske, M. 2012. Activation of calcium- and calmodulindependent protein kinase (CCaMK), the central regulator of plant root endosymbiosis. Curr. Opin. Plant Biol. 15:444-453.

Smith, S. E., and Read, D. J. 2008. Mycorrhizal Symbiosis, 3rd Ed. Academic Press, London, U.K.

Sugiura, Y., Akiyama, R., Tanaka, S., Yano, K., Kameoka, H., Marui, S., Saito, M., Kawaguchi, M., Akiyama, K., and Saito, K. 2020. Myristate can be used as a carbon and energy source for the asymbiotic growth of arbuscular mycorrhizal fungi. Proc. Natl. Acad. Sci. U.S.A. 117:25779-25788.

Sun, T. P. 2011. The molecular mechanism and evolution of the GAGID1-DELLA signaling module in plants. Curr. Biol. 21:R338-R345.

Wang, E., Schornack, S., Marsh, J. F., Gobbato, E., Schwessinger, B., Eastmond, P., Schultze, M., Kamoun, S., and Oldroyd, G. E. D. 2012. A common signaling process that promotes mycorrhizal and oomycete colonization of plants. Curr. Biol. 22:2242-2246.

Wang, E., Yu, N., Bano, S. A., Liu, C., Miller, A. J., Cousins, D., Zhang, X., Ratet, P., Tadege, M., Mysore, K. S., Downie, J. A., Murray, J. D., Oldroyd, G. E. D., and Schultze, M. 2014. A H+-ATPase that energizes nutrient uptake during mycorrhizal symbioses in rice and Medicago truncatula. Plant Cell 26:1818-1830.

Wang, W., Shi, J., Xie, Q., Jiang, Y., Yu, N., and Wang, E. 2017. Nutrient exchange and regulation in arbuscular mycorrhizal symbiosis. Mol. Plant 10:1147-1158.

Xue, L., Cui, H., Buer, B., Vijayakumar, V., Delaux, P. M., Junkermann, S., and Bucher, M. 2015. Network of GRAS transcription factors involved in the control of arbuscule development in Lotus japonicus. Plant Physiol. 167:854-871.

Yano, K., Yoshida, S., Müller, J., Singh, S., Banba, M., Vickers, K., Markmann, K., White, C., Schuller, B., Sato, S., Asamizu, E., Tabata S., Murooka, Y., Perry, J., Wang, T. L., Kawaguchi, M., ImaizumiAnraku, H., Hayashi, M., and Parniske, M. 2008. CYCLOPS, a mediator of symbiotic intracellular accommodation. Proc. Natl. Acad. Sci. U.S.A. 105:20540-20545.

Yu, N., Luo, D., Zhang, X., Liu, J., Wang, W., Jin, Y., Dong, W., Liu, J., Liu, H., Yang, W., Zeng, L., Li, Q., He, Z., Oldroyd, G. E., and Wang, E. 2014. A DELLA protein complex controls the arbuscular mycorrhizal symbiosis in plants. Cell Res. 24:130-133.

Zhang, C., He, J., Dai, H., Wang, G., Zhang, X., Wang, C., Shi, J., Chen, X., Wang, D., and Wang, E. 2021. Discriminating symbiosis and immunity signals by receptor competition in rice. Proc. Natl. Acad. Sci. U.S.A. 118:e2023738118.

Zhang, Q., Blaylock, L. A., and Harrison, M. J. 2010. Two Medicago truncatula half-ABC transporters are essential for arbuscule development in arbuscular mycorrhizal symbiosis. Plant Cell 22:1483-1497.

Zhang, X., Dong, W., Sun, J., Feng, F., Deng, Y., He, Z., Oldroyd, G. E. D., and Wang, E. 2015. The receptor kinase CERK1 has dual functions in symbiosis and immunity signalling. Plant J. 81:258-267.

Zipfel, C., and Oldroyd, G. E. 2017. Plant signalling in symbiosis and immunity. Nature 543:328-336. 